\title{
A novel pathway in NSCLC cells: miR-191, targeting NFIA, is induced by chronic hypoxia, and promotes cell proliferation and migration
}

\author{
JIA ZHAO ${ }^{1,2}$, CHENG-RUI QIAO ${ }^{1,2}$, ZHENG DING ${ }^{1,2}$, YIN-LIANG SHENG ${ }^{1,2}$, XIANG-NAN LI ${ }^{1,2}$, YANG YANG $^{1,2}$, \\ DENG-YAN ZHU ${ }^{1,2}$, CHUN-YANG ZHANG ${ }^{1,2}$, DONG-LEI LIU ${ }^{1,2}$, KAI WU ${ }^{1,2}$ and SONG ZHAO ${ }^{1,2}$ \\ ${ }^{1}$ Department of Thoracic Surgery, First Affiliated Hospital, Zhengzhou University; \\ ${ }^{2}$ Key Thoracic Tumour Experimental Laboratory of Zhengzhou, Zhengzhou, Henan 450052, P.R. China
}

Received July 6, 2015; Accepted April 25, 2016

DOI: $10.3892 / \mathrm{mmr} .2017 .6100$

\begin{abstract}
MicroRNAs (miRs) have emerged as being important in cancer biology. miR-191 is a conserved miRNA, which has been investigated in detail and is reported to be induced by hypoxia-inducible factor (HIF)-1 $\alpha$ and has an contributory action in the progression of breast, hepatic and pancreatic cancer. However, the effects of miR-191 in the progression of lung cancer are a subject of debate. In the present study, it was found that the expression of miR-191 was significantly upregulated in non-small cell lung cancer (NSCLC) cells in patients in vivo. However, the levels of miR-191 remained unchanged in SK-MES-1, A549 and NCI-H460 NSCLC cell lines, compared with the level in the normal HBE lung cell line, however, the levels were markedly upregulated in these NSCLC cell lines under conditions of chronic hypoxia. Subsequently, an miR-191 mimic was transfected into the NSCLC cell lines to examine its effect on the progression of the NSCLC cells in vitro. The data obtained using MTT and Cell counting kit- 8 assays revealed that miR-191 had no effect on the proliferation of the cells under normal condition, however, their proliferation was promoted under mild hypoxic conditions. In addition, the results of a Transwell migration assay showed that miR-191 had a promoting effect on NSCLC cell migration under the conditions of chronic hypoxia. Furthermore, the TargetScan bioinformatics server and 3'-untranslated region luciferase reporter assay indicated that the transcription factor, nuclear factor $1 \alpha$ (NFIA) was a target of miR-191. Subsequent western blot analysis showed that, in chronic-hypoxia, the protein levels of NFIA and the tumor suppressor, CCAAT-enhancer-binding protein $\alpha$, were sharply reduced in A549 cells. In conclusion,
\end{abstract}

Correspondence to: Dr Song Zhao, Department of Thoracic Surgery, First Affiliated Hospital, Zhengzhou University, 1 Jianshe East Road, Zhengzhou, Henan 450052, P.R. China

E-mail: songzhaozz@163.com

Key words: microRNA-191, non-small cell lung cancer, chronic hypoxia, proliferation and migration, nuclear factor $1 \alpha$
miR-191 was induced by chronic hypoxia and promoted the proliferation and migration of NSCLC cells under chronic hypoxic conditions. This promotion may be associated with its targeting of NFIA. The present findings may provide a potential molecular target for the therapeutic treatment of NSCLC.

\section{Introduction}

Lung cancer is one of the most common types of malignant tumor worldwide, and has become the leading contributor to rates of mortality in China during the past decade (1-3). Non-small cell lung cancer (NSCLC) accounts for $\sim 80 \%$ of all cases of lung cancer, and includes squamous cell carcinoma, adenocarcinoma and large cell carcinoma. Compared with small cell carcinoma, the growth and division of NSCLC cells are more rapid, and their diffusion and metastasis occur at a relatively early stage (4). In cases of NSCLC, $>50 \%$ of patients are found to be in the middle and advanced stages, and the 5 year survival rate is relatively low (4-6). The pathogenesis of NSCLC remains to be fully elucidated. Therefore, it is important to identify novel genes or factors, which regulate the progression of NSCLC.

Chronic hypoxia is an often slow, insidious reduction in tissue oxygenation. Hypoxia-inducible factors (HIFs) are expressed at high levels in response to hypoxia, and transcriptionally upregulates a series of genes causing metabolic alterations $(7,8)$. The decrease of oxygen supply usually results in significant functional changes of normal and cancerous cells. In normal cells, including neurons and myocytes, chronic hypoxia has been shown to cause a series of disorders in the cells and can even induce their apoptosis $(9,10)$. However, the roles of hypoxia in the functions of cancer cells differ substantially. It has been reported that chronic hypoxia has a promoting effect on cancer progression through regulating cancerous cell proliferation, metastasis and angiogenesis (11-13).

MicroRNAs (miRs) have emerged as being important in physiological and pathological biological processes. miR-191 is a conserved miRNA, which has been investigated in detail and has been identified as being transcribed from an intronic region of the gene, DALR anti-codon binding domain containing 3 (14). Induced by several master transcription 
factors, miR-191 has been reported to be abnormally expressed in $>20$ types of cancer and numerous other diseases, including obesity, type II diabetes, pulmonary hypertension and Alzheimer's disease $(15,16)$. miR-191 regulates cell proliferation, differentiation, apoptosis and migration by targeting important transcription factors, chromatin remodelers and cell cycle-associated genes (15). Several studies have demonstrated that miR-191 is a valuable biomarker for cancer diagnosis and prognosis $(17,18)$. A number of reports have shown that miR-191 can be induced by HIF-1 $\alpha$ and has a contributory action in the progression of breast, hepatic and pancreatic cancers (19-21). In patients with lung cancer, miR-191 has been found to be upregulated, suggesting that it may be involved in progression of lung cancer (22). However, a previous in vitro study indicated that the overexpression of miR-191 did not lead to changes in cell cycle, proliferation, xenograft formation or in the chemosensitivity of A549 lung adenocarcinoma and BEAS-2B normal lung cell lines (23). Whether miR-191 has any effects on the progression of NSCLC remains to be elucidated

In the present study, the expression of miR-191 was detected in the NSCLC tissues and adjacent matched normal tissues, as well as in human NSCLC cell lines and human normal lung cells, under both normal and hypoxic condition. Following this, miR-191 was overexpressed or silenced in A549 NSCLC cells under normal or hypoxic condition, and the exact role of miR-191 in cell proliferation and migration of NSCLC cells, and the potential mechanism were investigated. It was found that miR-191 had a significant impact on hypoxic NSCLC cells, however, not under normal conditions. The present study provided a novel insight into the regulation of NSCLC progression.

\section{Materials and methods}

Ethical statement and sampling. In the present study, 96 patients with middle- or late-stage NSCLC were recruited, comprising 32 patients with squamous cell cancer

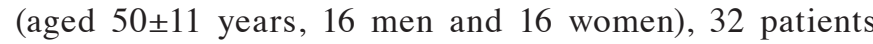

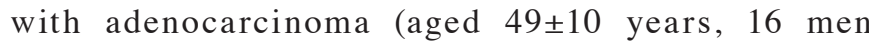
and 16 women) and 32 patients with large cell carcinoma (aged 52 \pm 12 years, 16 men and 16 women). Cancerous tissue and matched adjacent normal tissues were sampled from each subject during minimal invasive surgery. Tumor diameter ranged between 3 and $7 \mathrm{~cm}$. The present study was approved by the Ethical Committee of Zhengzhou University (Zhengzhou, China), and all the subjects provided written informed consent prior to participation in the investigation.

Cell culture and chronic hypoxia treatment. HBE normal lung cells, SK-MES-1 human lung squamous cell carcinoma cells, A549 human lung adenocarcinoma cells and NCI-H460 human lung large cell carcinoma cells were purchased from Shanghai Institutes for Biological Sciences (Shanghai, China). The cells were stored in liquid nitrogen and thawed in a $37^{\circ} \mathrm{C}$ water bath. The cells were centrifuged at $1,000 \mathrm{~g}$ for $7 \mathrm{~min}$, following which the HBE, SK-MES-1 and A549 cells were suspended in Dulbecco's modified Eagl's medium containing $4.5 \mathrm{~g} / 1$ glucose and $4 \mathrm{mmol} / \mathrm{l} \mathrm{L-glutamin}$ (Invitrogen; Thermo Fisher Scientific, Inc., Waltham, MA,
USA) supplemented with $10 \%$ fetal bovine serum (FBS; Invitrogen; Thermo Fisher Scientific, Inc.). The NCI-H460 cells were suspended in RPMI-1640 containing $4.5 \mathrm{~g} / 1$ glucose and $4 \mathrm{mmol} / \mathrm{l}$ L-glutamin supplemented with 10\% FBS. For treatment, the cells were seeded into 12 -well plates at a density of $10^{5} / \mathrm{cm}^{2}$. The cells were incubated in a humidified incubator with an atmosphere of $95 \%$ air $/ 5 \% \mathrm{CO}_{2}$ at $37^{\circ} \mathrm{C}$ until adhesion. For hypoxia treatment, the adherent cells were incubated in a humidified incubator with an atmosphere of $80 \% \mathrm{~N}_{2} / 15 \% \mathrm{O}_{2} / 5 \% \mathrm{CO}_{2}$ at $37^{\circ} \mathrm{C}$.

Transfection. A single-strand miRNA mimic negative control (NC) and miR-191 mimic were designed, synthesized and confirmed as effective by RiboBio Co., Ltd. (Guangzhou, China). On reaching $80 \%$ confluence, 6 pmol NC or 6 pmol miR-191 mimic were transfected into the cell lines using Lipofectamine 3000 (Invitrogen; Thermo Fisher Scientific, Inc.), according to the manufacturer's protocol. The medium was replaced every 3 days.

Cell proliferation and migration analysis. Cell proliferation was evaluated using MTT (Sigma-Aldrich, St. Louis, MO, USA) and Cell Counting kit-8 (Sigma-Aldrich) assays. Following treatment, the cells $\left(1 \times 10^{4}\right.$ cells/well $)$ were incubated at $37^{\circ} \mathrm{C}$ for $0,24,48$ and $72 \mathrm{~h}$ prior to the addition of MTT reagent to each well at a final concentration of $0.5 \mathrm{mg} / \mathrm{ml}$ and incubation at $37^{\circ} \mathrm{C}$ for $4 \mathrm{~h}$. Following removal of the medium, $500 \mu 1$ dimethyl sulfoxide was added to each well. The proportion of viable cells were measured by absorbance at a $550 \mathrm{~nm}$ wavelength using a microplate reader (BioRad Laboratories, Inc., Hercules, CA, USA). The Cell Counting kit-8 assay was performed, according to the manufacturer's protocol.

Migration was detected using a Transwell migration assay. The cell migration assay was performed using Matrigel (BD Biosciences, Sparks, MD, USA), which was coated on the upper surface of the Transwell chamber (Corning, Lowell, MA, USA). The cells, which migrated through the membrane were fixed with methanol and stained with crystal violet (Sigma-Aldrich). Images of three randomly selected fields of the fixed cells were captured, and cells numbers were counted using a Countess automatic cell counter (Invitrogen; Thermo Fisher Scientific, Inc.).

Reverse transcription-quantitative polymerase chain reaction (RT-qPCR). Total RNA was isolated using TRIzol reagent (Invitrogen; Thermo Fisher Scientific, Inc.), according to the manufacturer's protocol. The RNA concentration was quantified using a spectrophotometer measuring the optical density (OD)260/280 ratio (1.80-1.95). The integrity of the RNA was confirmed by electrophoresis on $1.0 \%$ agarose gel with ethidium bromide (Sigma-Aldrich) staining. RT was performed using a SuperScript II 1st Strand cDNA Synthesis kit (Invitrogen; Thermo Fisher Scientific, Inc.). The reaction was run in a $20 \mu \mathrm{l}$ system containing $2 \mu \mathrm{l}$ SuperScript ${ }^{\circledR}$ RT Enzyme Mix I, $8 \mu$ l SuperScript ${ }^{\circledR}$ Buffer, $2 \mu$ l Invitrogen NCode miRNA universal qPCR primer, $2 \mu 1$ RNA template, and $6 \mu \mathrm{l}$ RNase-free $\mathrm{H}_{2} \mathrm{O}$. The system was incubated at $42^{\circ} \mathrm{C}$ for $30 \mathrm{~min}$ and was subsequently incubated at $85^{\circ} \mathrm{C}$ for $15 \mathrm{sec}$ to finalize the reaction. The $\mathrm{qPCR}$ reactions were performed using a final sample volume of $25 \mu$, containing SYBR 
Premix Ex Taq (Takara Bio, Inc., Otsu, Japan), 0.4 mM of each primer and $200 \mathrm{ng}$ of cDNA template. The mature miR-191 stem-loop primer and quantitative primers, as well as the U6 RNA primers, were designed and produced by RiboBio Co., Ltd.). Primer sequences were as follows: U6, forward: 5'-CGC TTC GGC AGC ACA TAT AC-3' and reverse: 5'-TTC ACG AAT TTG CGT GTC AT-3" miR-191, forward: 5'-CAA CGG AAT CCC AAA AGC AGC T-3' and reverse: Invitrogen NCode miRNA universal qPCR primer. Each individual sample was run in triplicate wells. The PCR amplification cycles were performed using a $\mathrm{iQ}^{\mathrm{TM}} 5$ Multicolor Real-Time PCR Detection system (Bio-Rad Laboratories, Inc.) and a SYBR Premix Ex Taq II kit (Invitrogen; Thermo Fisher Scientific, Inc.). The reactions were initially denatured at $95^{\circ} \mathrm{C}$ for $3 \mathrm{~min}$, followed by 35 cycles of $95^{\circ} \mathrm{C}$ for $15 \mathrm{sec}$ and $60^{\circ} \mathrm{C}$ for $60 \mathrm{sec}$. The data were quantified using the $2^{-\Delta \Delta \mathrm{Cq}}$ method (24). The quantities of mRNA were normalized to that of U6 RNA.

3'UTR luciferase reporter assay. The cDNA fragment corresponding to the 3'UTR of NFIA mRNA, containing the binding site of miR-191 with XhoI and Not I cutting sites, was constructed and confirmed by sequencing. The fragments were cloned into psiCHECK ${ }^{\mathrm{TM}}-2$ vectors (Promega, Madison, WI, USA) at the 3'-end of the Renilla gene. The HEK293T cells $\left(20 \times 10^{3}\right)$ were seeded into 96-well plates for $24 \mathrm{~h}$, following which transfection was performed using 1.0 $\mu$ l Lipofectamine 3000 transfection reagent (Roche, Mannheim, Germany), $100 \mathrm{ng}$ of the vector constructs, and $50 \mathrm{nM}$ of either the miR-191 mimic or NC per well. The cells were harvested $48 \mathrm{~h}$ following transfection. Luciferase activity was measured using a DualGlo Luciferase Assay system (Promega). Renilla luciferase activity was measured and normalized to the corresponding firefly luciferase activity.

Western blot analysis. The total proteins were extracted using a Total Protein Extraction kit (BestBio, Shanghai, China) and quantified using a BCA Protein assay kit (Merck, Whitehouse Station, NJ, USA), according to the manufacturer's protocols. Equal quantities of protein $(20 \mu \mathrm{g})$ from each sample were separated by $12 \%$ SDS-PAGE and electro-transferred onto polyvinylidene fluoride membranes (EMD Millipore, Billerica, MA, USA) for immunoblotting analysis. The membranse were blocked using blocking buffer (Abcam, Cambridge, UK) overnight at $4^{\circ} \mathrm{C}$. The following primary antibodies were used: Anti-CCAAT-enhancer-binding protein $\alpha(\mathrm{C} / \mathrm{EBP} \alpha$; 1:200; cat. no. ab8227; Abcam), anti-NFIA (1:300; cat. no. ab41851; Abcam) and anti- $\beta$-actin $(1: 200$; cat. no. ab32358; Abcam), which was used as the internal reference. The antibodies were diluted in 5\% non-fat milk in tris-buffered saline containing Tween-20 (TBST) and the incubation was for $2 \mathrm{~h}$ at $37^{\circ} \mathrm{C}$. Following washing three times (8 min each) with TBST, the membranes were incubated with goat anti-rabbit horseradish-peroxidase-conjugated secondary antibody (cat. no. ab6721; 1:2,000; Abcam) for $1 \mathrm{~h}$ at $37^{\circ} \mathrm{C}$. The membranes were washed as before and the the proteins were detected using a ChemiDoc XRS imaging system and Quantity One version 4.62 analysis software (Bio-Rad Laboratories, Inc.).
Prediction software. The targeting association between NFIA and miR-191 was predicted using the online server, TargetScan (http://www.targetscan.org/cgi-bin/targetscan/vert_61/view_ gene.cgi?taxid=9606\&rs=NM_001134673 \&members=miR-1 $91 \&$ showcnc $=0 \&$ shownc $=0$ ).

Statistical analysis. All data were obtained from at least three independent experiments. Values are expressed as the mean \pm standard error of the mean. Statistical analyses were performed using SPSS 19.0 (IBM SPSS, Armonk, NY, USA). Multiple comparisons were assessed using one-way analysis of variance followed by Dunnett's tests. $\mathrm{P}<0.05$ was considered to indicate a statistically significant difference.

\section{Results}

Expression of miR-191 is significantly upregulated in NSCLC cells under chronic hypoxic conditions. The expression levels of mature miR-191 in cancerous tissues and adjacent non-cancerous tissues from the patients with NSCLC were detected using RT-qPCR analysis. The results demonstrated that the levels of miR-191 were significantly upregulated in the cancerous tissues, compared with the adjacent tissues (Fig. 1A). However, the data obtained from the lung cancer cell lines showed that there were no significant differences in the levels of miR-191 between the normal lung cell line and the NSCLC cell lines (Fig. 1B-D). Subsequently, the NSCLC cells were incubated in a chronic hypoxic environment $(15 \%$ $\mathrm{O}_{2}$ ). It was found that the levels of miR-191 were markedly upregulated in response to chronic hypoxia, compared with the cells under normal conditions (Fig. 1B-D). These data suggested that miR-191 may be involve in the progression of NSCLC cells under chronic hypoxic conditions.

Overexpression of miR-191 has no effect on the proliferation of NSCLC cell lines under normal conditions, but promotes their proliferation under chronic hypoxic conditions. To investigate the role of miR-191 in the progression of NSCLC in vitro, the $\mathrm{NC}$ mimic or miR-191 mimic were transfected into the SK-MES-1, A549 and NCI-H460 human NSCLC cell lines under normal conditions and chronic hypoxic conditions. The proliferation of the cells were then detected using an MTT assay. The results showed that miR-191 had no effect on the proliferation of these three cell lines (Fig. 2A-C), whereas transfection with the miR-191 mimic led to significant promotion of the proliferation of the cells under chronic hypoxic conditions (Fig. 2D-F). The data obtained from the CCK-8 assay also indicated that the overexpression of miR-191 promoted the proliferation of the cells under chronic hypoxic conditions (Fig. 3A-C).

Overexpression of miR-191 promotes the migration of NSCLC cell lines under chronic hypoxic conditions. Subsequently, the role of miR-191 in the migration of NSCLC cell lines under hypoxic conditions was investigated. Following transfection, the migration of the NSCLC cells was detected using a Transwell migration assay. The results of the crystal violet staining and cell counting revealed that miR-191 promoted the migration of the cells under chronic hypoxic conditions (Fig. 3D and $\mathrm{E})$. 
A

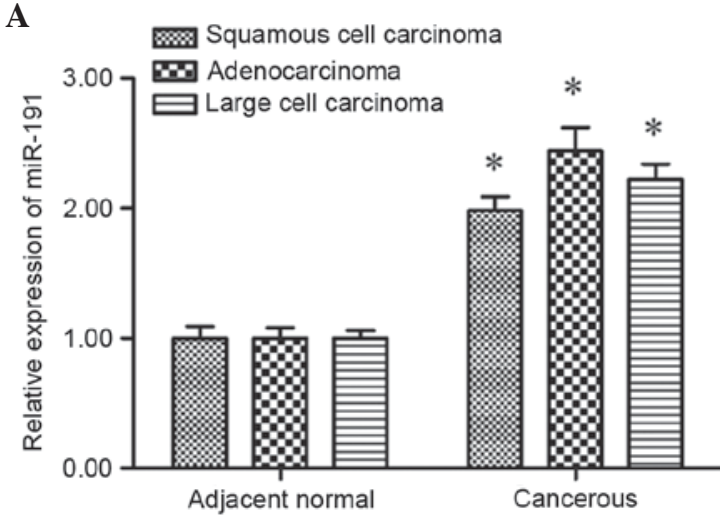

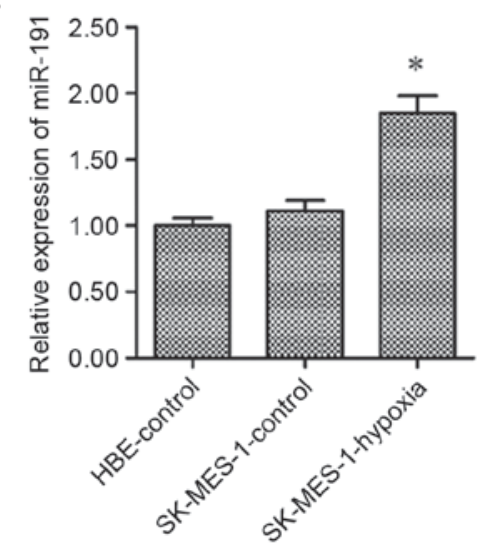

C

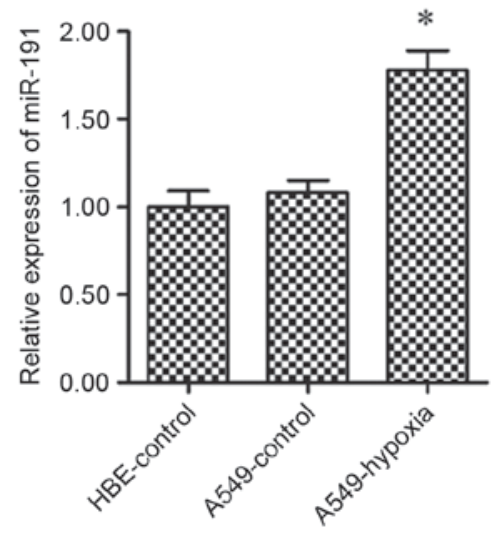

D

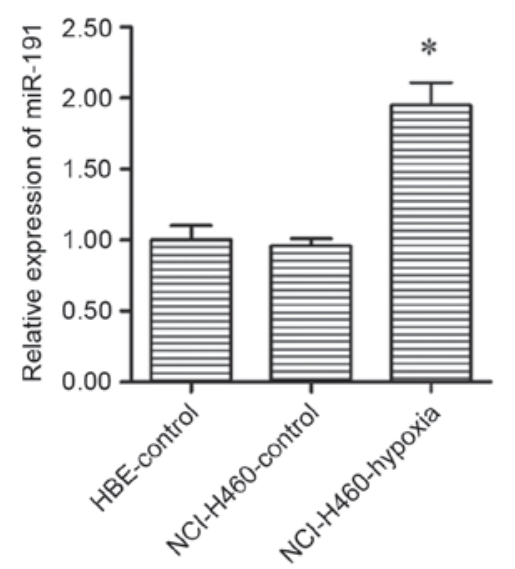

Figure 1. miR-191 is upregulated in NSCLC tissues and NSCLC cell lines under chronic hypoxic conditions. (A) miR-191 was upregulated in lung tissues from patients with NSCLC. (B) Comparison between levels of miR-191 among normal HBE-control cells, SK-MES-1 cells under normal conditions and SK-MES-1 cells under mild hypoxic conditions with 15\% $\mathrm{O}_{2}$. (C) Comparison between levels of miR-191 among HBE normal lung cells, A549 lung adenocarcinoma cells under normal conditions and A549 cells under mild hypoxic conditions with $15 \% \mathrm{O}_{2}$. (D) Comparison between levels of miR-191 among HBE normal lung cells, NCI-H460 lung large-cell carcinoma cells under normal conditions and $\mathrm{NCI}-\mathrm{H} 460$ cells under a mild hypoxic conditions with $15 \% \mathrm{O}_{2}$.Data are presented as the mean \pm standard error of the mean. ${ }^{*} \mathrm{P}<0.05$, vs. HBE-control. NSCLC, non-small cell lung cancer; miR, microRNA.

A

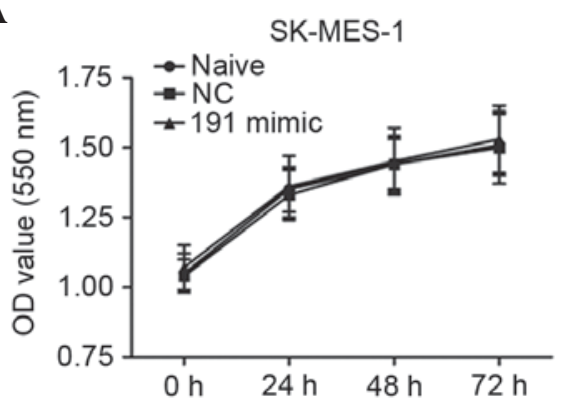

D

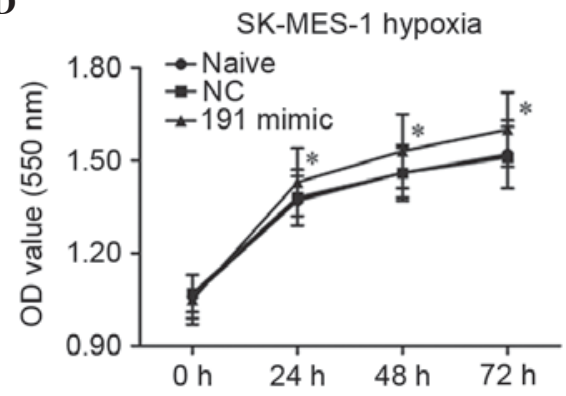

B

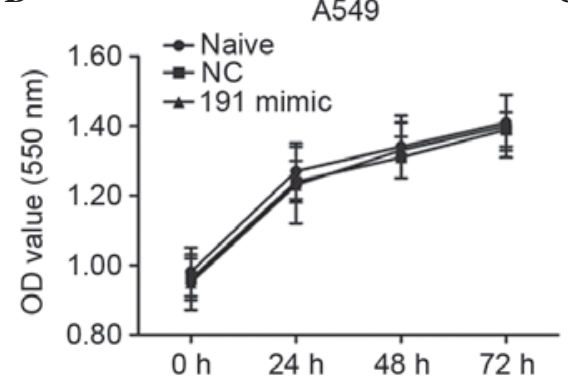

$\mathbf{E}$

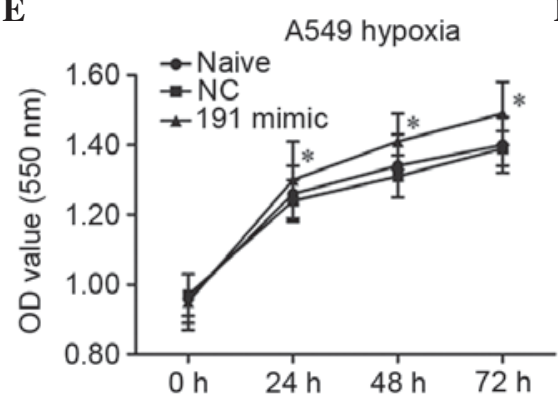

C

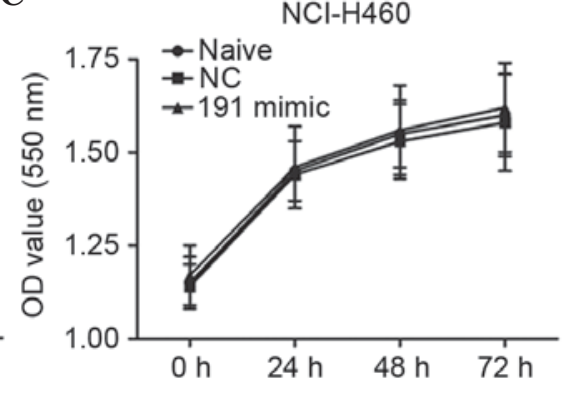

$\mathbf{F}$

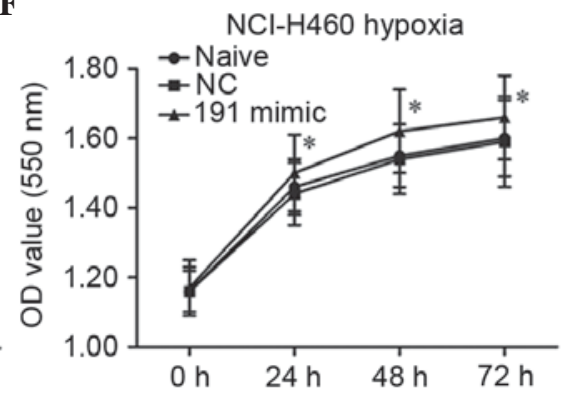

Figure 2. Overexpression of miR-191 promotes NSCLC cell proliferation under chronic hypoxic conditions. The effect of miR-191 on the proliferation of (A) SK-MES-1, (B) A549 and (C) NCI-H460 cells were determined using an MTT assay under normal conditions. The effect of miR-191 on the proliferation of the (D) SK-MES-1, (E) A549 and (F) NCI-H460 NSCLC cells were determined using an MTT assay under a mild hypoxic conditions with $15 \% \mathrm{O}_{2}$. Data are presented as the mean \pm standard error of the mean ${ }^{*} \mathrm{P}<0.05$, vs. naïve. NSCLC, non-small cell lung cancer; OD, optical density; $\mathrm{NC}$, negative control. 
A

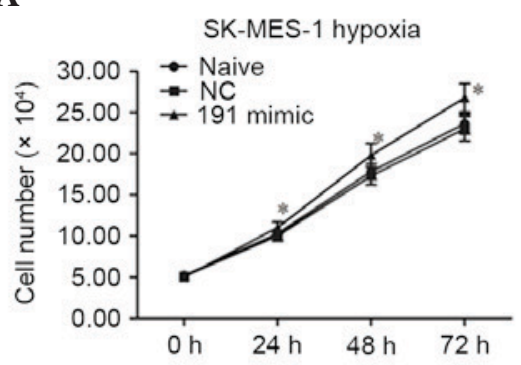

B

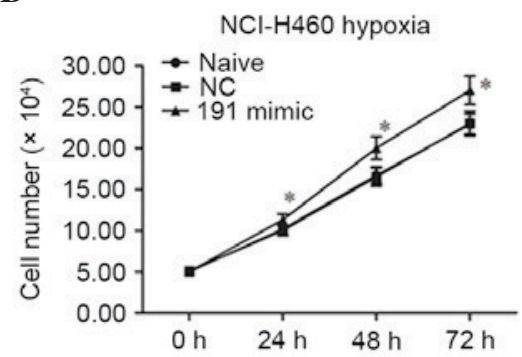

C

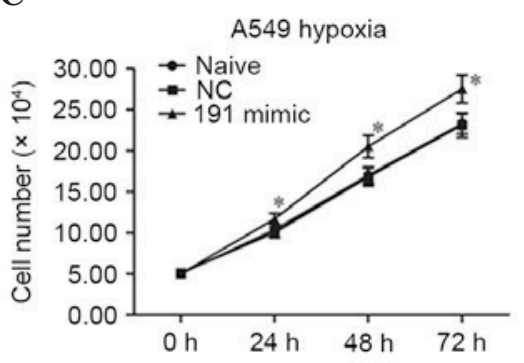

D
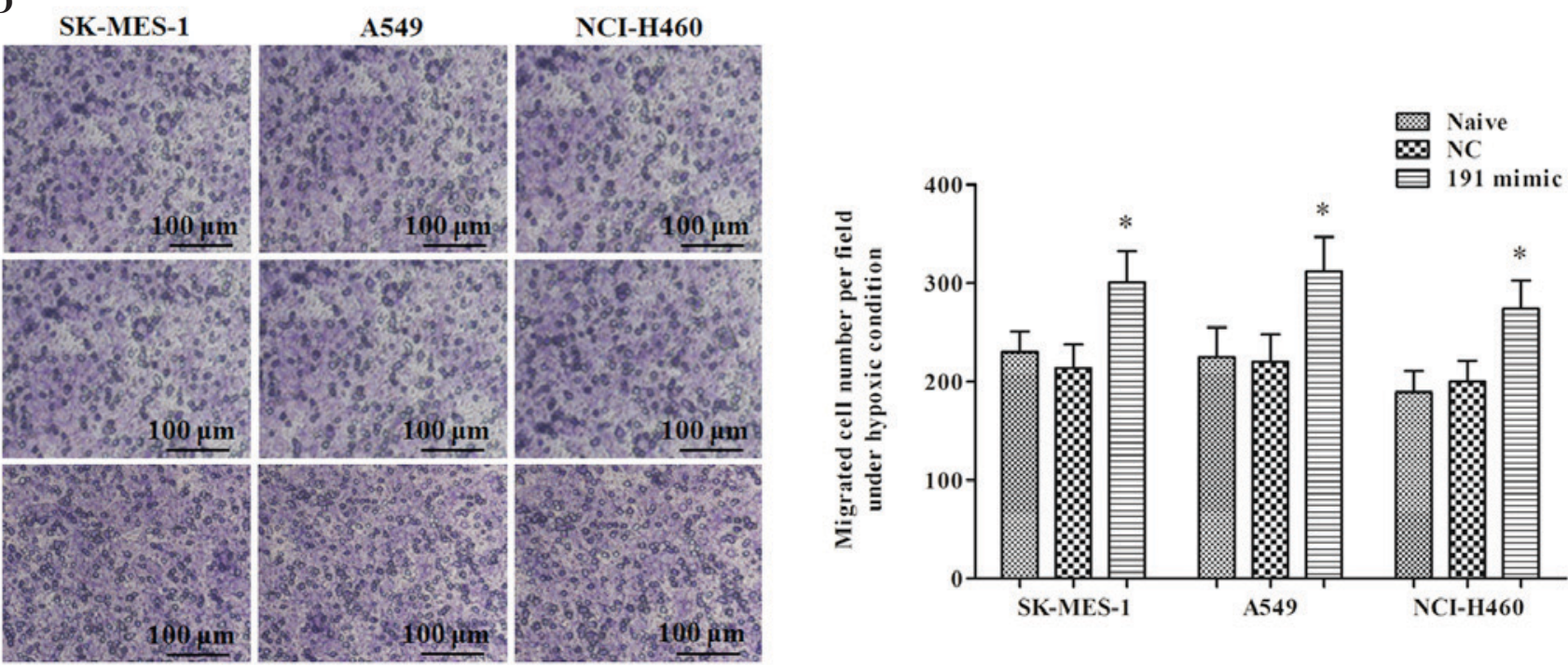

Figure 3. Overexpression of miR-191 promotes the migration of NSCLC cells under chronic hypoxic conditions. The effects of miR-191 on the proliferation of (A) SK-MES-1, (B) A549 and (C) NCI-H460 cells, determined using a Cell Counting kit-8 assay under a mild hypoxic condition swith $15 \% \mathrm{O}_{2}$. (D) Effects of miR-191 on the migration of NSCLC cells were determined using a Transwell migration assay under a mild hypoxic conditions. Following transfection with 6 pmol 191 mimic or NC mimic for 48 h, the cells were seeded into the Transwell plate. Following incubation for another $24 \mathrm{~h}$, the migrated cells were fixed with methanol, stained with crystal violet and observed under a microscope. Scale bar=1 cm. Data are presented as the mean \pm standard error of the mean. ${ }^{*} \mathrm{P}<0.05$, vs. naïve. NSCLC, non-small cell lung cancer; miR, microRNA; NC, negative control.

miR-191 targets NFIA and negatively regulates the tumor-suppressing NFIA-C/EBP $\alpha$ axis. To examine the mechanism underlying the miR-191-induced promotion of proliferation and migration in the NSCLC cell lines, the online server, TargetScan, was accessed to identify its potential target genes. The output of TargetScan showed that the NFIA mRNA was perfectly matched by the miR-191 seed sequence at the 3'UTR region (Fig. 4A). The 3'UTR luciferase reporter assay was then applied to validate their targeting association. The data showed that miR-191 markedly reduced the relative fluorescence intensity (Fig. 4B), which supported the results described above. In addition, western blot analysis of the A549 cells showed that the protein expression of NFIA was markedly reduced by miR-191mimic transfection (Fig. 4C). Its downstream tumor suppressing gene, $\mathrm{C} / \mathrm{EBP} \alpha$ was also suppressed (Fig. 4C).

\section{Discussion}

The role of miR-191 in lung cancer has been disputed. Certain studies have reported that the expression of miR-191 is stable in NSCLC, and that overexpression of miR-191 does not lead to changes in cell cycle, proliferation, xenograft formation or the chemosensitivity of lung adenocarcinoma cells in vitro $(23,25)$. However, in other studies, miR-191 has been found to be upregulated in patients with lung cancer, suggesting that it may be involved in the progression of lung cancer. A study by Nadal et al involved profiling 61 lung squamous cell carcinoma tissues and 10 matched adjacent normal lung tissues using miRNA arrays, and it was concluded that miR-191 in the serum was a predictor of prognosis in surgically resected lung squamous cell carcinoma $(22,26)$.

In the present study, the results showed that expression levels of miR-191 were significantly upregulated in the lung tissues of patients with middle- and late-stage NSCLC. However, the overexpression of miR-191 did not lead to changes in the proliferation of the SK-MES-1, A549 or NCI-H460 NSCLC cell lines under normal conditions $\left(20 \% \mathrm{O}_{2} / 5 \% \mathrm{CO}_{2}\right)$. This suggested that there are certain important distinctions between the in vitro and in vivo environments of NSCLC cells. Studies have revealed that HIF- $1 \alpha$ is induced in the advanced stages of several types of cancer (27-30), suggesting that NSCLC cells are adversely affected by a hypoxic environment in patients. Therefore, the present study hypothesized that miR-191 may be induced by hypoxia, and affect the progression of NSCLC under hypoxic conditions. The data from the MTT and CCK-8 assays demonstrated that miR-191 promoted the proliferation of NSCLC under mild hypoxic conditions $\left(15 \% \mathrm{O}_{2}\right)$. 
A

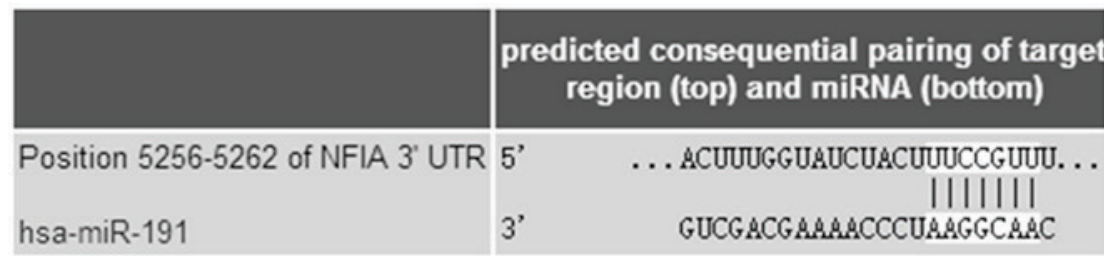

B

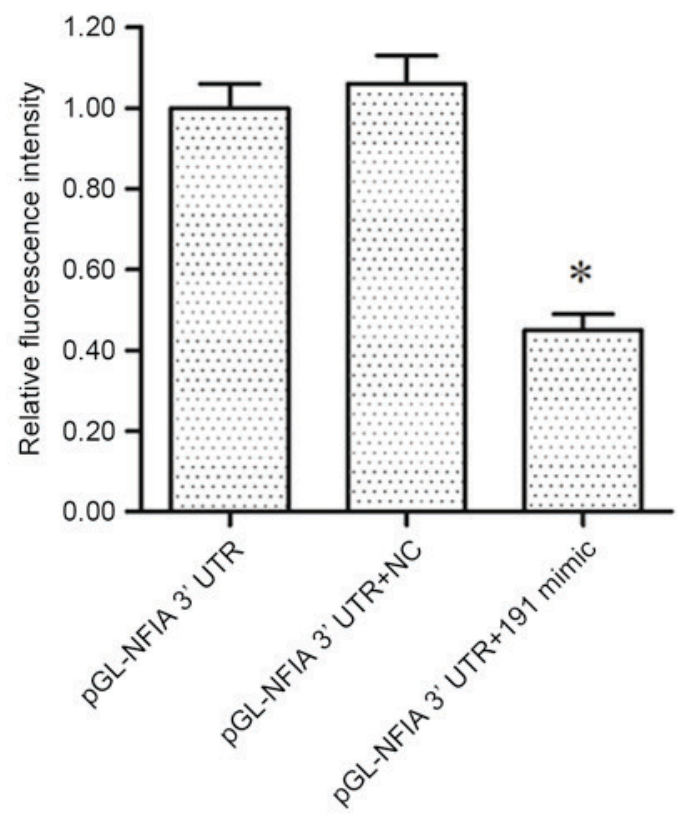

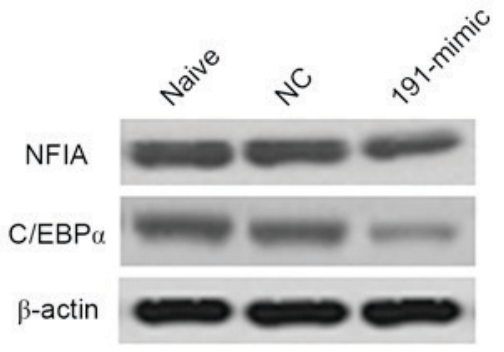

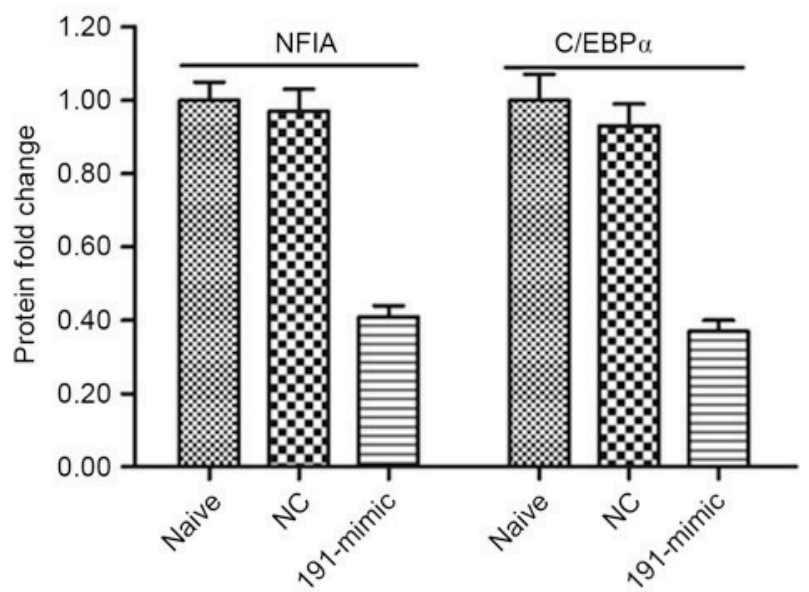

Figure 4. NFIA is target of miR-191. (A) Output of TargetScan for prediction of the association between miR-191 and NFIA. (B) 3'UTR luciferase reporter assay for the targeting association between miR-191 and NFIA mRNA. (C) Western blot analysis of the protein levels of NFIA and C/EBP $\alpha$. Following transfection with the mimics for $48 \mathrm{~h}$ under chronic hypoxic conditions, the cells were collected, and the protein levels of NFIA and C/EBP $\alpha$ were detected. Data are presented as the mean \pm standard error of the mean. ${ }^{*} \mathrm{P}<0.05$, vs. control/naive. NSCLC, non-small cell lung cancer; miR, microRNA; NC, negative control; 3'UTR, 3'untranslated region; NFIA, nuclear factor $1 \alpha$; C/EBP $\alpha$, CCAAT-enhancer-binding protein $\alpha$.

NFIA is a key regulator of gene expression in normal and cancerous cells. A previous study showed that the miR-223/ NFIA axis suppressed tumorigenesis in a human glioma cell line (31). In the present study, the output of TargetScan showed that NFIA mRNA was perfectly matched by the miR-191 seed sequence at the 3'UTR region. A 3'UTR luciferase reporter assay showed that miR-191 markedly reduced the relative fluorescence intensity, supporting the results described above. The western blot analysis revealed that the protein levels of NFIA and its downstream tumor suppressing gene, C/EBP $\alpha$, was markedly reduced by miR-191 mimic transfection. These results contradicted those of previous reports in other types of cancer $(31,32)$. However, the results of a study on astrocytoma indicated that NFIA is associated with improved survival rates (33). The results of the present study suggested that NFIA has a negative effect on the progression of NSCLC.

In conclusion, the present study demonstrated that miR-191 was upregulated in patients with middle- and latestage NSCLC, and in NSCLC cell lines, under mild hypoxic conditions. miR-191 promoted the proliferation and migration of NSCLC under chronic hypoxic conditions, and this promotion may be associated with its targeting of NFIA. These results indicated that miR-191 promoted NSCLC progression, which may provide novel insight for the regulation of NSCLC progression under chronic hypoxic conditions.

\section{References}

1. Torre LA, Bray F, Siegel RL, Ferlay J, Lortet-Tieulent J and Jemal A: Global cancer statistics, 2012. CA Cancer J Clin 65: 87-108, 2015.

2. Chen W, Zheng R, Zhang S, Zhao P, Zeng H and Zou X: Report of cancer incidence and mortality in China, 2010. Ann Transl Med 2: 61, 2014.

3. Chen WQ, Zheng RS, Zhang SW, Zeng HM and Zou XN: The incidences and mortalities of major cancers in China, 2010. Chin J Cancer 33: 402-405, 2014.

4. McKee MD, Bondarenko I, Guclu SZ, et al: Veliparib (ABT-888) or placebo combined with carboplatin and paclitaxel in patients with previously untreated advanced/metastatic squamous (Sq) non-small cell lung cancer (NSCLC): A randomized phase 3 trial. In: ASCO Annual Meeting Proceedings, p TPS8107, Chicago, IL, 2015. 
5. Goldstraw P, Ball D, Jett JR, Le Chevalier T, Lim E, Nicholson AG and Shepherd FA: Non-small-cell lung cancer. Lancet 378: 1727-1740, 2011

6. Ettinger DS, Akerley W, Borghaei H, Chang AC, Cheney RT, Chirieac LR, D'Amico TA, Demmy TL, Ganti AK, Govindan R, et al: Non-small cell lung cancer. J Natl Compr Canc Netw 10: 1236-1271, 2012

7. Li H, Chen SJ, Chen YF, Meng QC, Durand J, Oparil S and Elton TS: Enhanced endothelin-1 and endothelin receptor gene expression in chronic hypoxia. J Appl Physiol (1985) 77: 1451-1459, 1994.

8. Smith TG, Robbins PA and Ratcliffe PJ: The human side of hypoxia-inducible factor. Br J Haematol 141: 325-334, 2008.

9. Parvin A, Pranap R, Shalini U, Devendran A, Baker JE and Dhanasekaran A: Erythropoietin protects cardiomyocytes from cell death during hypoxia/reperfusion injury through activation of survival signaling pathways. PLoS One 9: e107453: 2014.

10. Huang W, Liu X, Cao J, Meng F, Li M, Chen B and Zhang J: miR-134 regulates ischemia/reperfusion injury-induced neuronal cell death by regulating CREB signaling. J Mol Neurosci 55: 821-829, 2015.

11. Simon MC: Abstract IA13: A hypoxic microenvironment influences pancreatic cancer progression. Cancer Res 75 IA13-IA13, 2015.

12. Shay JE, Imtiyaz HZ, Sivanand S, Durham AC, Skuli N, Hsu S, Mucaj V, Eisinger-Mathason TS, Krock BL, Giannoukos DN and Simon MC: Inhibition of hypoxia-inducible factors limits tumor progression in a mouse model of colorectal cancer. Carcinogenesis 35: 1067-1077, 2014.

13. Amelio I and Melino G: The p53 family and the hypoxia-inducible factors (HIFs): Determinants of cancer progression. Trends Biochem Sci 40: 425-434, 2015.

14. Zhang L, Flygare J, Wong P, Lim B and Lodish HF: miR-191 regulates mouse erythroblast enucleation by down-regulating Riok3 and Mxi1. Genes Dev 25: 119-124, 2011.

15. Nagpal N and Kulshreshtha R: miR-191: An emerging player in disease biology. Front Genet 5: 99, 2014.

16. Di Leva G and Croce CM: miRNA profiling of cancer. Curr Opin Genet Dev 23: 3-11, 2013

17. Liu R, Chen X, Du Y, Yao W, Shen L, Wang C, Hu Z, Zhuang R, Ning G, Zhang C, et al: Serum microRNA expression profile as a biomarker in the diagnosis and prognosis of pancreatic cancer. Clin Chem 58: 610-618, 2012.

18. Collins AL, Wojcik S, Liu J, Frankel WL, Alder H, Yu L, Schmittgen TD, Croce CM and Bloomston M: A differential microRNA profile distinguishes cholangiocarcinoma from pancreatic adenocarcinoma. Ann Surg Oncol 21: 133-138, 2014.

19. Nagpal N, Ahmad HM, Chameettachal S, Sundar D, Ghosh S and Kulshreshtha R: HIF-inducible miR-191 promotes migration in breast cancer through complex regulation of TGF $\beta$-signaling in hypoxic microenvironment. Sci Rep 5: 9650, 2015.

20. He Y, Cui Y, Wang W, Gu J, Guo S, Ma K and Luo X: Hypomethylation of the hsa-miR-191 locus causes high expression of hsa-mir-191 and promotes the epithelial-to-mesenchymal transition in hepatocellular carcinoma. Neoplasia 13: 841-853, 2011.
21. Song Z, Ren H, Gao S, Zhao X, Zhang H and Hao J: The clinical significance and regulation mechanism of hypoxia-inducible factor-1 and miR-191 expression in pancreatic cancer. Tumor Biol 35: 11319-11328, 2014

22. Volinia S, Calin GA, Liu CG, Ambs S, Cimmino A, Petrocca F, Visone R, Iorio M, Roldo C, Ferracin M, et al: A microRNA expression signature of human solid tumors defines cancer gene targets. Proc Natl Acad Sci USA 103: 2257-2261, 2006.

23. Patnaik SK, Kannisto E and Yendamuri S: Overexpression of microRNA miR-30a or miR-191 in A549 lung cancer or BEAS-2B normal lung cell lines does not alter phenotype. PloS One 5: e9219, 2010.

24. Zhou W, Wang G, Zhao X, Xiong F, Zhou S, Peng J, Cheng Y, $\mathrm{Xu} \mathrm{S}$ and $\mathrm{Xu} \mathrm{X}$ : A multiplex qPCR gene dosage assay for rapid genotyping and large-scale population screening for deletional $\alpha$-thalassemia. J Mol Diagn 15: 642-651, 2013.

25. Markou A, Sourvinou I, Vorkas PA, Yousef GM and Lianidou E: Clinical evaluation of microRNA expression profiling in non small cell lung cancer. Lung Cancer 81: 388-396, 2013.

26. Nadal E, Chen G, Chang AC, Lin J, Reddy R, Orringer MB and Beer DG: Ratio of miR-146b/miR-191 in serum predicts prognosis in surgically resected lung squamous cell carcinomas. Cancer Res 72: 4147, 2012.

27. Puisségur MP, Mazure NM, Bertero T, Pradelli L, Grosso S, Robbe-Sermesant K, Maurin T, Lebrigand K, Cardinaud B, Hofman V, et al: miR-210 is overexpressed in late stages of lung cancer and mediates mitochondrial alterations associated with modulation of HIF-1 activity. Cell Death Differ 18: 465-478, 2011.

28. Elson DA, Ryan HE, Snow JW, Johnson R and Arbeit JM: Coordinate up-regulation of hypoxia inducible factor (HIF)-1alpha and HIF-1 target genes during multi-stage epidermal carcinogenesis and wound healing. Cancer Res 60: 6189-6195, 2000.

29. Wang N, Dong CR, Jiang R, Tang C, Yang L, Jiang QF, Chen GG and Liu ZM: Overexpression of HIF-1 $\alpha$, metallothionein and SLUG is associated with high TNM stage and lymph node metastasis in papillary thyroid carcinoma. Int $\mathbf{J}$ Clin Exp Pathol 7: 322-330, 2013.

30. Wu Y, Mao F, Zuo X, Moussalli MJ, Elias E, Xu W and Shureiqi I: 15-LOX-1 suppression of hypoxia-induced metastatic phenotype and HIF-1 $\alpha$ expression in human colon cancer cells. Cancer Med 3: 472-484, 2014

31. Liu C, Duan P, Li B, Huang C, Jing Y and Yan W: miR-29a activates Hes1 by targeting Nfia in esophageal carcinoma cell line TE-1. Oncol Lett 9: 96-102, 2015

32. Lee JS, Xiao J, Patel P, Schade J, Wang J, Deneen B, Erdreich-Epstein A and Song HR: A novel tumor-promoting role for nuclear factor IA in glioblastomas is mediated through negative regulation of p53, p21, and PAI1. Neuro Oncol 16: 191-203, 2014.

33. Song HR, Gonzalez-Gomez I, Suh GS, Commins DL, Sposto R, Gilles FH, Deneen B and Erdreich-Epstein A: Nuclear factor IA is expressed in astrocytomas and is associated with improved survival. Neuro Oncol 12: 122-132, 2010. 